\title{
Characterisation of lignocellulosic sugars from municipal solid waste residue.
}

\begin{abstract}
Municipal solid waste (MSW) contains significant quantities of plant-derived carbohydrates which have the potential to be exploited as a biomass source. This study evaluated the chemical composition and fractionation of MSW water-insoluble organic matter remaining after recycling of other components (MSWR). The organic matter was prepared as a dry, alcohol insoluble residue (MSWR-AIR, comprising $\mathrm{w}=6 \%$ of original MSW) and size fractionated into fractions A, B, C \& D. Carbohydrates were present in all the sub-fractions, comprising up to $\mathrm{w}=54 \%$; their complexity was also assessed by FT-IR spectroscopy. The lignin content in the samples ranged from $\mathrm{w}=11-22 \%$. The most carbohydrate-rich subfraction $(\mathrm{C} ; \mathrm{w}=4 \%$ original $\mathrm{MSW}$ ) was sequentially extracted to provide information on the likely constituent cell wall-derived polymers, sugar compositions and uronic acid content. The results indicate that approximately $\mathrm{w}=25 \%$ of the MSWR-AIR comprises glucose, which appears to be mostly cellulosic in origin. The results are discussed in relation to the potential for exploitation.
\end{abstract}

Keyword: Municipal solid waste; Composition; Cell walls; Polysaccharides; Sequential extraction. 